\title{
Impact of national culture on the severity of the COVID-19 pandemic
}

\author{
Yasheng Chen ${ }^{1} \cdot$ Mohammad Islam Biswas ${ }^{2,3}$ (1) \\ Accepted: 11 February 2022 \\ (c) The Author(s), under exclusive licence to Springer Science+Business Media, LLC, part of Springer Nature 2022
}

\begin{abstract}
This study examines how cultural differences can affect the transmission of COVID-19 in different countries. From a sample of 92 countries, we used cross-country data based on Hofstede's cultural dimensions to investigate the impact of culture on COVID-19 transmission. We found a significant impact of culture on the spread of COVID-19. Specifically, this study reveals that individualism, masculinity, and uncertainty avoidance have a positive impact on confirmed COVID-19 cases. The relationships between cultural differences and the total number of COVID-19 deaths were also positive. This study provides valuable insights into the influences that national culture could have on the effectiveness of responses to a similar global pandemic situation in the future.
\end{abstract}

Keywords COVID-19 $\cdot$ Hofstede $\cdot$ National culture $\cdot$ Transmission outcomes

\section{Introduction}

COVID-19 is spreading globally as an infectious disease. According to Yan et al. (2020), differences in human behavior are affecting the spread of this deadly virus. Similarly. Lunn et al. (2020) argued that beyond governmental policies, humans' individual and collective behaviors, which differ among countries, also determine the spread of this virus. Governments worldwide have taken unprecedented preventive measures (e.g., maintaining lockdowns, advocating social distancing, urging people to wear face masks, and encouraging hygienic practices) to minimize the spread of this infectious virus. However, preventive measures implemented by governments cannot be imposed entirely by force; their success depends on individuals' compliance. For instance, the impact of social distancing and lockdowns is evident in New Zealand and China, particularly when

Mohammad Islam Biswas

biswas8042@gmail.com

Yasheng Chen

yshchen@xmu.edu.cn

1 Department of Accounting, Xiamen University, Xiamen, China

2 Institute of Financial and Accounting Studies, Xiamen University, Xiamen, China

3 Department of Accounting, Bangladesh University of Business and Technology (BUBT), Dhaka, Bangladesh compared with some European countries. In addition, the US and Brazil were slower in implementing lockdown and social distancing and did not more sporadically than China (Anderson et al., 2020; Greenstone \& Nigam, 2020).

We have observed differences across countries in terms of outcomes; while the virus is the same, it affects people differently in terms of the severity of the disease. The differences appear to correspond to how the government and people in each respective country respond to COVID-19. Some cross-country comparison studies have provided evidence that culture is one of a range of factors responsible for explaining such cross-country differences (Han et al., 2010; Hult et al., 2008). We seek here to focus only one of those factors; no study has revealed that culture is an important aspect that explains cross-culture differences in COVID19 transmission. Thus, we can discuss the importance of culture in the transmission of this infectious disease because, for example, many cases of COVID-19 are spread by people who have no symptoms (Oran \& Topol, 2020). A frequent absence of symptoms is one of COVID-19's major characteristics. Infected people with no symptoms can get very sick and often die later. However, it has been observed that COVID-19 has an uncommon feature at the no-symptoms stage: infected people are contagious even in the absence of symptoms. This means that anyone can potentially be carrying and spreading the virus because it takes a long-time for symptoms to show. Stopping one's movement during the asymptomatic period would therefore be in the interest 
of the infected person as well as society. Additionally, it is in the public interest to quarantine infected persons during the asymptomatic period. If the infected person stops moving around, they cannot infect others. This is a typical example of individualism. We can argue that, as the example of asymptomatic COVID-19 transmission clearly shows, culture may play a role. For this reason, the issue deserves systemic examination. We, therefore, sought to examine all cultural dimensions of Hofstede to determine which cultural dimension(s) play a greater role.

Different countries have diverse cultures that influence inhabitants' attitudes and social behaviors, as well as government policies, in the face of public health events. For instance, Gelfand et al. (2011) argued that European countries, the US and Canada, are loose cultures, whereas Asian cultures, as strict cultures, have imposed strict measures and punishments for deviance. Alfano and Ercolano (2020) claimed that strict cultures (e.g., China, South Korea, and Singapore) succeeded in controlling the pandemic by imposing restrictive measures (e.g., lockdowns, social distancing, and wearing a face mask); whereas other countries argued that a lockdown was unnecessary (e.g., Sweden) or must be lifted quickly (e.g., the US). Research has also found that cultural tightness-looseness is associated with limiting confirmed COVID-19 cases and deaths (Cao et al., 2020; Gelfand et al., 2021).

This study investigated the impact of national culture on the severity of the COVID-19 pandemic. Further, we reveal which of Hofstede's cultural dimension(s) have greater influence in this regard. Following Liu et al. (2020), we measure the transmission outcome of COVID-19 by the total number of confirmed cases and total deaths. We also use the growth rate and effective reproduction number $\left(\mathrm{R}_{\mathrm{t}}\right)$ to measure the virus transmission outcome. Based on a sample of 92 countries' Hofstede cultural dimensions' scores and COVID-19 data, we found a strong association between individuals' cultural differences and the transmission of COVID-19.

\section{Literature Review and Hypotheses}

Culture is a broad term that includes social behavior, norms, individuals' knowledge, beliefs, arts, laws, customs, abilities, and habits (Tylor, 1871). Culture relies on conventional beliefs, ideas, habits, traditions, and values (Triandis, 2001) that affect and guide an individual's societal behavior. Similarly, Henrich (2015) argued that culture involves values held by individuals with a particular nationality in a particular social setting. However, such an individual's behavior is acquired, created, developed, and transmitted by a group of people to subsequent generations. In sum, human behaviors are primarily and significantly influenced by a nation's culture. National culture consists of common beliefs, attitudes, feelings, thinking, shared values, and means among a country's citizens. The role of national culture has been studied by previous researchers in different fields (Triandis, 2001; Willmott, 2000).

Several scholars have used different approaches to clarify and explain the importance of national cultural differences (Brockner, 2003; Tsui et al., 2007). Prior researchers have also developed theories and models to explain the cultural value of workplace behaviors, attitudes, and other organizational outcomes (Hellriegel et al., 1992; Hofstede, 1980; Trompenaars, 1994). The national cultural dimensions of Hofstede are one of the most popular, widely used, and most frequently cited in the cross-cultural framework. As a psychologist, Hofstede initially examined how employees from different disciplines and nations perceived four dimensions, namely power distance, individualism, uncertainty avoidance, and masculinity. Two other dimensions-long-term orientation and indulgence-later evolved through a value survey. Researchers have used Hofstede's national cultural dimensions in different fields, including economics, business, and human-computer interactions (Chan \& Yan, 2016; Tsui et al., 2007).

\section{How Some Preventive Measures Work During COVID-19}

Absent an effective treatment at the beginning of the COVID-19 pandemic, governments of different countries took various measures to control its spread. Huynh (2020) claimed that some preventive measures could reduce COVID-19 transmission, such as maintaining a lockdown and social distancing, using a face mask, contact tracing, and isolating ill people. For example, some countries (e.g., China and South Korea) have succeeded in controlling the pandemic by imposing lockdowns and social distancing; whereas others argue that a lockdown is unnecessary (e.g., Sweden) or must be lifted quickly (e.g., the US) (Alfano \& Ercolano, 2020). On the other hand, Italy and Spain were initially slower to implement lockdowns, which caused the severe spread of COVID-19 and people's suffering. Therefore, Greenstone and Nigam (2020) argued that a lockdown is the more effective measure of social distancing, whereby governments force citizens to limit their movements. Although the risk perception of this virus and the understandings of the pandemic were unclear and not the same in all countries, there was no doubt that strict lockdowns could control the spread of the virus (Félix et al., 2021; Li et al., 2021). The intervention actions taken by governments around the world are not the same; this might be because of cultural differences, which are examined in this study.

The best guidance from public health officials in every country is to send clear messages that individuals need to change their behavior to contain the coronavirus pandemic. 
Social distancing is one of these important behaviors of individuals. Huynh (2020) proved the success of social distancing during a global pandemic. They emphasized that the importance of timing and length of this preventive strategy are relatively essential to control the pandemic. A statistical analysis of confirmed cases and deaths in Italy and Spain shows that the pandemic began to decline only after introducing strict social distancing (Khataee et al., 2021). Comparing social distancing measures in China, South Korea, Italy, France, and the United States indicated that the initial doubling time for confirmed cases was approximately two days, which was significantly delayed by implementing social distancing in these countries (Hsiang et al., 2020). Similarly, Greenstone and Nigam (2020) claimed that at the beginning of the pandemic, if the US and European countries had restrained from social gatherings and close contact at a personal level, virus spread could have been reduced.

Lunn et al. (2020) conducted an experimental study using a sample of 500 respondents to explore how social distancing motivates people in Ireland. Their study found that the participants' understanding of the severity of the infectious virus could lead to changes in individual behavior. Meanwhile, Huynh (2020) claimed that despite facts, it is the logical processing of information, not psychological reactions, that primarily drives humans. However, countries have implemented social distancing differently. For example, Anderson et al. (2020) asserted that the success of China, New Zealand, South Korea, and Singapore in handling the outbreak is partly attributable to individual social distancing behaviors. This new virus shows interesting, unique responses in different communities and countries, highlighting the effect of cultural complexities on pandemic-related reactions. Therefore, culture plays a vital role in assessing disease attributions, helping to determine individuals' behaviors and pathways and community willingness to comply with pandemic-spread measures.

At the beginning of the pandemic, wearing a face mask was one of the most controversial issues. However, substantial evidence exists to support the logic of wearing a face mask in public places to lower the infection rate (Greenhalgh et al., 2020). In certain situations, the extensive use of face masks seems to reduce infection rates, although other factors affect an outbreak in a region. For example, Vietnam, after first implementing a face mask mandate, recorded 99 days in a row, with no case of in-the-bunch spread. ${ }^{1}$ Similarly, Matthay et al. (2020) argued that the universal face mask use in public places in China, South Korea, and Singapore has been successful in controlling the virus. In contrast, in some European countries and the US, the issue of wearing

${ }^{1}$ https://www.cfr.org/in-brief/which-countries-are-requiring-facemasks a face mask is slowing implementation of earlier mandates and revealing civic sometimes political fault lines. This difference is attributable to cultural differences and the widespread social norms affecting different countries' responses during the pandemic.

Contact tracing and the isolating of symptomatic cases was an early preventive measure in many countries (e.g., South Korea and Singapore), as well as maintaining a lockdown, following social distancing, and wearing a face mask. However, Huynh (2020) emphasized that the effectiveness of contact tracing relies on the quality of health facilities and social interactions among populations. Kucharski et al. (2020) argued that the effectiveness of social distancing, isolation, and contact tracing are containment measures for reducing COVID-19 infection. Using data on over 40,000 individuals from the UK, they analyzed contact patterns and possible COVID-19 infections in various ways and compared how contact tracing, self-isolation, and social distancing are able to reduce confirmed cases.

\section{Culture and Human Behavior Under COVID-19}

In the theoretical context, we examined the possible cultural impact of individual behaviors on the transmission of the COVID-19 pandemic. It has been proven that individuals' behaviors are based mainly on the actions of others members of society (Gelfand et al., 2011). Therefore, social norms and the roles of culture drive individual behavior heterogeneously. For instance, Gelfand et al. (2011) argued that European countries, the US and Canada, are loose cultures, whereas Asian cultures, as strict cultures, have imposed strict and punishable social distancing rules. Some researchers, such as Gelfand et al. (2021) concluded that strict cultures are correlated with population density, natural disasters, and previous outbreaks of different diseases. Thus, countries with strict cultures form communities to organize people to work together during any crisis period. In contrast, countries with loose cultures prioritize individual freedom and privacy. From this point of view, this feature has a link with the cultural dimensions of Hofstede that people from individualistic and collectivistic countries follow governments' preventive measures (e.g., maintaining a lockdown and social distancing, using a face mask, etc.) differently to contain the transmission of COVID-19.

Previous studies have shown that cultural values are associated with human pathogens. For instance, Fincher et al. (2008) analyzed cross-cultural data and concluded that countries with a higher pathogen incidence had lower individualism and higher collectivism scores. Similarly, Kim et al. (2016) found a positive relationship between collectivism and perceived vulnerability increased for Ebola and xenophobia. Although individualism is negatively related to the purpose of social distance practice, collectivism has 
been found to be positively related to perceived concerns and anxieties about the risk of COVID-19 infection (Biddlestone et al., 2020; Xiao, 2021). A study of country-level collectivism in 98 countries found a link between confirmed COVID-19 cases and mortality rates and country-level collectivism (Webster et al., 2021). However, collectivism is positively related to following different preventive measures (Lu et al., 2021). On the other hand, collectivism and power distance can work together to influence public perception of the collective action of the COVID-19 preventive system (Xiao, 2021). For example, China, as a collectivistic and high power distance country, has succeeded in controlling COVID-19 transmission compared to individualistic and low power distance countries.

Political polarization and social media are two important cultural aspects that affect human behavior (e.g., power distance and masculinity). Cherneski (2020) offered a cultural perspective on how social media and news discussions surrounding the COVID-19 outbreak presented a potentially changing hegemonic description of masculine leadership. However, Hetherington and Weiler (2009) claimed that in some countries, information popularization might lead people to have fewer political beliefs. Thus, individuals in these countries might believe false information that induces incorrect decision-making in a crisis period, such as COVID-19. Therefore, political opinion and social media might eventually influence cultural dimensions of individual behavior, particularly the power distance index and femininity versus masculinity of Hofstede measurements.

People's decision-making involves uncertainty during a pandemic because if people feel high risk, they prefer to avoid uncertainties (Huynh, 2020). Additionally, those who are risk-averse might commit themselves to effective preventive measures. Furthermore, Gelfand et al. (2011) showed that individuals' behaviors largely depend on the behaviors of others in society. However, cultures also differ in the degree to which they accept uncertainty. For example, at the beginning of the COVID-19 outbreak, Italy and Spain took some time to implement the preventive measures (e.g., maintaining lockdowns and social distancing, using a face mask), and people were allowed to catch the disease; in contrast, other European countries (e.g., Germany, and the Netherlands) adopted a defensive strategy from the beginning (Plümper \& Neumayer, 2020). Therefore, looking at the dimension of uncertainty can show how people responded to the uncertain situations of the COVID-19 outbreaks.

Culture is a crucial factor in understanding social policy development. Countries with long-term orientation scores might plan before incurring any crisis, but COVID-19 is a severe crisis that very few countries were ready to face. Nations with short-term orientation scores are likelier to implement hypervigilance and preventive measures in this dimension. High indulgence societies have weaker control over the impulses of a global pandemic, whereas tightculture nations can implement control measures such as lockdowns and social distancing as a common part of their regular processes. Consequently, cultural differences influence the decision-making process.

Heppner (2008) claimed that culture could help clarify the diverse policies accepted by people to manage unpredicted events. The unprecedented spreading speed of COVID-19 poses one of the greatest epidemiological threats a society could face. The transmission speed of the pandemic can be measured by the number of confirmed cases over a period (Liu et al., 2020). Numbers of confirmed COVID-19 cases vary from country to country. Taken together, prior discussion on individual cultural differences and the COVID-19 pandemic lead us to the first hypothesis:

H1: Individual cultural dimensions are positively associated with the confirmed COVID-19 cases.

The differences between countries in their ability to limit COVID-19 deaths might be associated with cultural variations in the social norms (Gelfand et al., 2021). Psychology has recognized the power of social norms to hinder individuals' behavior. However, countries around the world differ greatly in their adherence to individualism. While the world is in the COVID-19 crisis, governments worldwide are acting to control the crisis, but existing national cultures can help shape individuals' behavior and lead to significantly different outcomes (Xiao, 2021). Therefore, we predict a positive impact of cultural differences on COVID-19 deaths. This study's second hypothesis is as follows:

H2: Individual cultural dimensions are positively associated with the COVID-19 related deaths.

While the world is in the COVID-19 crisis, governments worldwide are acting to control the crisis, but existing national cultures can help shape individuals' behavior and lead to significantly different outcomes. Individual behavior determines the growth rate of confirmed cases, which varies from country to country. Therefore, we predict a positive impact of cultural differences on the growth rate of confirmed COVID-19 cases, and this study's third hypothesis is as follows:

H3: Individual cultural dimensions are positively associated with the growth rate of confirmed COVID-19 cases.

The origin of COVID-19 is not yet known; however, its rapid transfer from person to person has been widely confirmed. We used an effective reproduction number $\left(R_{t}\right)$ to measure infectious disease transmission. $R_{t}$ is the average number of secondary cases in a specific population created 
Table 1 Panel A: Sample selection process. Panel B: Sample countries

1. Total number of countries listed in the John Hopkins University Corona Virus Resource Center

2. Less: Countries with incomplete data on all six cultural dimensions of Hofstede

3. Total countries with complete data on all cultural dimensions of Hofstede

Continents

Asia

Europe

North America

South America

Africa

Oceania
192

$\underline{100}$

$\underline{92}$

Countries

Armenia, Azerbaijan, Bangladesh, China, India, Indonesia, Iran, Iraq, Japan, Jordan, Kazakhstan, South Korea, Lebanon, Malaysia, Pakistan, Philippines, Saudi Arabia, Singapore, Thailand, Turkey, Vietnam

Albania, Austria, Belarus, Belgium, Bosnia \& Herzegovina, Bulgaria, Croatia, Czech Republic, Denmark, Estonia, Finland, France, Georgia, Germany, Greece, Hungary, Iceland, Ireland, Italy, Latvia, Lithuania, Luxembourg, Malta, Moldova, Montenegro, Netherlands, North Macedonia, Norway, Poland, Portugal, Romania, Russia, Serbia, Slovenia, Slovenia, Spain, Sweden, Switzerland, Ukraine, United Kingdom

Canada, Dominican Republic, El Salvador, Mexico, Trinidad \& Tobago, Venezuela, USA

Argentina, Bolivia, Brazil, Chile, Colombia, Paraguay, Peru

Algeria, Angola, Burkina Faso, Cabo Verde, Egypt, Ghana, Libya, Morocco, Mozambique, Nigeria, Sao Tome \& Principe, South Africa, Tanzania, Zambia

Australia, New Zealand by a typical case (Yamauchi et al., 2019). $R_{t}$ is also considered a parameter to follow during the pandemic and estimates infectious disease transmission (Caicedo-Ochoa et al., 2020). When the relative threshold of $R_{t}$ is 1.0 or higher, the expected number of infected cases is predicted to increase; if $\mathrm{R}_{\mathrm{t}}$ is below 1.0, case numbers are expected to decrease (Yamauchi et al., 2019). However, Caicedo-Ochoa et al. (2020) used $R_{t}$ at the beginning of the pandemic to estimate the stage transmissibility of this infectious virus in some Latin American countries and found that $\mathrm{R}_{\mathrm{t}}$ is greater than 2.0. The global $R_{t}$ is more than $1.0 .^{2}$ Therefore, our last hypothesis is as follows.

H4: Individual cultural dimensions are positively associated with the COVID-19 effective reproduction number (Rt).

\section{Research Methodology}

\section{Sample and Data}

Panel A and Panel B of Table 1 outline the sample selection process and sample countries, respectively. The initial sample consisted of 192 countries. We dropped 100 countries for which the data on Hofstede's six cultural dimensions scores

\footnotetext{
$\overline{2}$ https://epiforecasts.io/covid/posts/global/
}

were not available. Using Hofstede's six cultural dimensional scores, we finally worked with a sample of 92 countries.

The sample included the total number of confirmed COVID-19 cases and deaths in 92 countries upto September 2021 from the COVID-19 Data Repository by the Center for Systems Science and Engineering (CSSE) at Johns Hopkins University. Then, we retrieved daily confirmed cases from the CSSE over the same period to calculate the growth rate. Finally, we retrieved the effective reproduction number $\left(R_{t}\right)$ from the Centre for Mathematical Modelling of Infectious Diseases (CMMID) at the London School of Hygiene \& Tropical Medicine. We used Hofstede's 6-dimensional cultural index as a measure of cultural differences and downloaded the country-wide scores of each dimension from hofstede-insights.com (see also Table 2).

\section{Research Design}

To examine the impact of culture on the COVID-19 pandemic transmission, we employed correlation and regression approaches for empirical analysis. We used multiple indicators to measure the severity of the COVID-19, as no single measure could fully capture the complexity in evaluating the effectiveness of cultural responses to the pandemic (Cao et al., 2020). In addition to the major cultural dimensions, we also controlled a number of important variables to examine how national culture influenced the COVID-19 transmission. Therefore, we used the following regression models to test the hypotheses: 
Table 2 Description and sources of variables

Description and sources of variables

\begin{tabular}{|c|c|c|}
\hline Variables & Description & Data sources \\
\hline Confirmed cases & $\begin{array}{l}\text { Number of total infected people by each } \\
\text { country }\end{array}$ & $\begin{array}{l}\text { COVID-19 Data Repository by } \\
\text { the Center for Systems Science } \\
\text { and Engineering (CSSE) at }\end{array}$ \\
\hline Deaths & Number of total deaths by each country & Johns Hopkins University \\
\hline Growth rate & $\begin{array}{l}\text { Average growth rate of confirmed cases by } \\
\text { each country }\end{array}$ & \\
\hline $\mathrm{R}_{\mathrm{t}}$ & Effective reproduction number by each country & CMMID \\
\hline Power distance & $\begin{array}{l}\text { Extent to which less powerful people accept } \\
\text { and expect an unequal distribution of power }\end{array}$ & \\
\hline Individualism & $\begin{array}{l}\text { Extent to which ties individuals are loose } \\
\text { (opposite of collectivism) }\end{array}$ & \\
\hline $\begin{array}{l}\text { Uncertainty } \\
\text { avoidance }\end{array}$ & $\begin{array}{l}\text { Degree to which individuals feel threatened by } \\
\text { unfamiliar situations }\end{array}$ & \\
\hline Masculinity & $\begin{array}{l}\text { Degree to which gender rules are clearly } \\
\text { distinct }\end{array}$ & hofstede-insights.com \\
\hline $\begin{array}{l}\text { Long-term } \\
\text { orientation }\end{array}$ & $\begin{array}{l}\text { How people present future-oriented } \\
\text { perspectives instead of short-term views }\end{array}$ & \\
\hline Indulgence & $\begin{array}{l}\text { Free gratification of natural human life related } \\
\text { to having fun and enjoying life }\end{array}$ & \\
\hline $\begin{array}{l}\text { Health } \\
\text { expenditure }\end{array}$ & Health expenditure of GDP by each country & The World Rank \\
\hline Population & Population density by each country & \\
\hline Corruption index & Measure government efficiency & Transparency International \\
\hline Time & $\begin{array}{l}\text { Time difference (days) between the first } \\
\text { infected case in Wuhan, China, and the } \\
\text { first infected case in each country }\end{array}$ & $\begin{array}{l}\text { COVID-19 Data Repository by } \\
\text { the Center for Systems Science } \\
\text { and Engineering (CSSE) at } \\
\text { Johns Hopkins University }\end{array}$ \\
\hline
\end{tabular}




$$
\begin{aligned}
& \text { Log }_{\text {Confirmedcases }}=\beta_{0}+\beta_{1} \text { Culture }+\beta_{2} \text { Resources } \\
& +\beta_{3} \text { Capacity }+\beta_{4} \text { Focus }+\beta_{5} \text { Time }+\varepsilon \\
& \text { Log Deaths }_{i t}=\beta_{0}+\beta_{1} \text { Culture }+\beta_{2} \text { Resources }+\beta_{3} \text { Capacity } \\
& +\beta_{4} \text { Focus }+\beta_{5} \text { Time }+\varepsilon \\
& \text { Growth rate }_{i t}=\beta_{0}+\beta_{1} \text { Culture }+\beta_{2} \text { Resources }+\beta_{3} \text { Capacity } \\
& +\beta_{4} \text { Focus }+\beta_{5} \text { Time }+\varepsilon \\
& R_{t \text { it }}=\beta_{0}+\beta_{1} \text { Culture }+\beta_{2} \text { Resources }+\beta_{3} \text { Capacity } \\
& +\beta_{4} \text { Focus }+\beta_{5} \text { Time }+\varepsilon
\end{aligned}
$$

where,

it $=\mathrm{i}$ means each country and t means the period

Log confirmed cases $=$ Log value of total confirmed cases of COVID-19 by country

$\log$ deaths $=\log$ value of the total number of deaths by country

Growth rate $=$ average growth of confirmed cases by country (growth rate is calculated by (current date/ previous date)- 1 and then average it)

$\mathrm{R}_{\mathrm{t}}=$ effective reproduction number by country

Culture $=$ six cultural dimensions of Hofstede

Resources $=$ health expenditure out of GDP by country

Capacity $=$ population density of each country

Focus $=$ corruption score by country

Time $=$ time difference (days) between the first infected case in Wuhan, China, and the first infected case in each other country

$\varepsilon=$ residual

\section{Variable Measurement}

The study constructed the following independent, dependent, and control variables using data from different sources. Table 2 presents a brief description and sources of variables.

\section{Culture}

To measure individuals' cultural differences, we adopted Hofstede's cultural dimensions. These cultural dimensions are one of the most common, widely used, and most frequently cited throughout the cultural context in various disciplines (Chan \& Yan, 2016; Tsui et al., 2007). In the original context, Hofstede put forward four dimensions: power distance, individualism, masculinity, and uncertainty avoidance. Hofstede later added the fifth and sixth dimensions: long-term orientation and indulgence.

Power distance measures the extent to which less powerful people within organizations accept and expect that power is not distributed equally (Hofstede et al., 2010, p. 61). This is exhibited, for example, in the relationships between subordinates and superiors, children and parents, youths and elders, etc. Countries with high power distance are characterized by unequal distribution of income, authoritarian leadership, and hierarchical structures; while countries with low power distance demonstrate an equal distribution of income, power, and more pluralist leadership. Individualism is defined as the extent to which individuals' ties are loose (i.e., the opposite of collectivism) ( Hofstede et al., 2010, p. 91). People in individualistic societies prefer to follow their own goals, achievements, freedoms, and self-interest, and governments have limited influence on individuals' actions. In contrast, in a collectivistic culture, people are integrated and subordinated to groups, often family-based, which require loyalty, and the performance of individuals is aimed at the group's goal. Uncertainty avoidance explores the uncertain circumstances and tolerance of ambiguity in society and the extent to which people can manage unknown, surprising, and unidentified situations (Hofstede et al., 2010, p. 189). Countries with high uncertainty avoidance index try to minimize everything by strict rules and laws and safety and security measures. In uncertainty-accepting societies impose fewer regulations, are more accustomed to ambiguity, and the environment flows more freely.

Masculinity is described as a preference for achievements, accomplishments, personal benefits, wealth, the materialism of status, and ambitions in society (Hofstede et al., 2010, p. 137). The opposite represents a predilection for cooperation, modesty, concern for the weak, and a high standard of living. Women in their respective societies display different values. In feminine cultures, they share an equally modest and caring attitude with men. Women are somewhat competitive and assertive in high masculine societies, but significantly less than men. Long-term orientation reveals how people present futureoriented perspectives instead of short-term views (Hofstede et al., 2010, p. 239). Short-term-oriented societies specify that traditions are respected and upheld, while steadfastness is admired. Long-term-oriented societies view adaptation and situational, realistic problem solving as essential. Countries with long-term oriented continue to develop and achieve economic success, while short-term based countries usually have very little to no economic development. The final dimension, indulgence, describes the free fulfillment of human life related to life's fun and enjoyment (Hofstede et al., 2010, p. 280). The opposite society controls the gratification of needs and regulates it through strict social rules.

COVID-19 The infectious disease called COVID-19 is caused by SARS-CoV-2, and transmission occurs from 
Table 3 Pearson's correlation among variables

\begin{tabular}{|c|c|c|c|c|c|c|c|c|c|c|c|c|c|c|}
\hline & CONC & Deaths & GOR & $\mathrm{R}_{\mathrm{t}}$ & PODIS & IND & MAS & UNTAV & LTO & IDUG & HCE & POP & CORR & TIME \\
\hline CONC & 1.00 & & & & & & & & & & & & & \\
\hline Deaths & $.96 * * *$ & 1.00 & & & & & & & & & & & & \\
\hline GOR & $.65 * * *$ & $.61 * * *$ & 1.00 & & & & & & & & & & & \\
\hline $\mathrm{R}_{\mathrm{t}}$ & -.14 & -.13 & $-.20 *$ & 1.00 & & & & & & & & & & \\
\hline PODIS & .02 & .02 & .04 & .18 & 1.00 & & & & & & & & & \\
\hline IND & $.24^{*}$ & $.22 *$ & .10 & -.05 & $-.72 * * *$ & 1.00 & & & & & & & & \\
\hline MAS & $.29 * *$ & $.32 * *$ & .03 & .03 & .08 & .09 & 1.00 & & & & & & & \\
\hline UNAV & $.21 *$ & $.28 * *$ & $.29 * *$ & $-.19 * *$ & $.32 * *$ & $-.25^{*}$ & .01 & 1.00 & & & & & & \\
\hline LTO & .16 & .12 & -.01 & -.09 & .02 & .17 & .04 & .18 & 1.00 & & & & & \\
\hline IDUG & -.14 & -.14 & -.07 & -.02 & $-.30 * *$ & .14 & -.01 & $-.26^{*}$ & $-.45^{* * *}$ & 1.00 & & & & \\
\hline $\mathrm{HCE}$ & .15 & .10 & .06 & .03 & $-.72 * * *$ & $.74 * * *$ & -.04 & $-.27 *$ & .16 & $.29 * *$ & 1.00 & & & \\
\hline POPU & $.24^{*}$ & $.26^{* *}$ & -.01 & .17 & .10 & -.04 & .16 & $-.26^{*}$ & .13 & -.13 & -.07 & 1.00 & & \\
\hline CORR & .01 & -.07 & -.02 & .06 & $-.64 * * *$ & $.59 * * *$ & -.12 & $-.28 * *$ & $.25^{*}$ & .17 & $.71 * * *$ & -.12 & 1.00 & \\
\hline TIME & $-.33 * *$ & $-.30 * *$ & .14 & -.19 & $.30 * *$ & $-.39 * * *$ & -.10 & $.22 *$ & $-.27 * *$ & .05 & $-.37 * * *$ & $-.35 * * *$ & $-.32 * *$ & 1.00 \\
\hline
\end{tabular}

${ }^{*} p<.05 ; * * p<.01 ; * * * p<.001$

This table shows the correlation matrix among the variables. Here, CONC means the log total confirmed cases, Deaths are the total log deaths. GOR means the growth rate, and $\mathrm{R}_{\mathrm{t}}$ is the effective reproduction number. PODIS, IND, MAS, UNTAV, LTO, IDUG are power distance, individualism, masculinity, uncertainty avoidance, long-term orientation, and indulgence, respectively. HCE, POP, CORR, TIME indicate health care expenditure of GDP, population density, corruption, and timing issue, respectively

person to person. ${ }^{3}$ Liu et al. (2020) used confirmed cases and total deaths to forecast the spreading speed of this virus under different models. Because this study's aim is to investigate the individuals' cultural impacts on COVID-19 transmission, we used the number of infected cases and deaths to measure cultural impacts. In our baseline analysis, we also used the average growth rate of each country on a given date. The average growth rate was calculated to match the virus transmission with individuals' cultural differences. $R_{t}$ is a parameter to track the pandemic and estimate infectious disease transmission (Caicedo-Ochoa et al., 2020). Therefore, we used $\mathrm{R}_{\mathrm{t}}$ to measure the transmission rate of this virus.

\section{Control Variables}

This study used four control variables: health care expenditure out of GDP, population density, corruption, and the timing issue. Maridal (2013) showed that culture's impact on economic growth and capacity could be measured by per capita GDP. Economic growth and health care facilities could have a significant effect on pandemic control (Ibanez $\&$ Sisodia, 2020). Thus, we used the health care expenditure out of GDP as the measurement of the health expenditure capacity of a country. People and culture have an inextricable relationship because cultural differences influence human psychology, and population density is a proxy

\footnotetext{
3 https://www.who.int/health-topics/coronavirus\#tab=tab_1
}

variable. Bentzen (2012) argued that corruption is bad for economic development and harms countries' productivity levels. As a control variable, we used the corruption index to measure each country's government efficiency. In countries that discovered COVID-19 at an early stage, both the government and the public took various measures to control its spread. Therefore, we selected timing issue as a control variable to measure the time difference (days) between the first infected case in Wuhan, China, and the first infected case in each individual other country.

\section{Data Analyses and Results}

We used the total confirmed cases, deaths, and growth rate as the key indicators for the spreading speed of COVID-19, and $R_{t}$ is considered a parameter to follow up infectious disease transmission. Because population size differs among countries, using proportional cases to measure the severity of this pandemic is much more reliable and will allow more accurate analysis than using absolute cases.

Table 3 shows the Pearson's correlation among the variables to measure the transmission of the COVID-19 pandemic across countries. The number of confirmed cases and deaths are positively correlated with individualism, masculinity, and uncertainty avoidance, which indicates that countries with strong individualism, high uncertainty avoidance, and strong masculine culture are positively associated with the number of confirmed cases and deaths during the COVID19 pandemic. While the growth rate of confirmed cases is 
Table 4 Regression results of confirmed cases on cultural dimensions and control variables

\begin{tabular}{llll}
\hline Dependent variable: & & & \\
\hline Confirmed Cases & $(1) \beta(\mathrm{SE})$ & $(2) \beta(\mathrm{SE})$ & $(3) \beta(\mathrm{SE})$ \\
\hline Power distance & $.457(.292)$ & & $.563(.304)$ \\
Individualism & $.890(.287) * * *$ & $.669(.300) *$ \\
Masculinity & $.444(.194) *$ & & $.340(.186) *$ \\
Uncertainty avoidance & $.451(.205) *$ & $.714(.211) * * *$ \\
Long-term orientation & $-.012(.221)$ & & $-.247(.230)$ \\
Indulgence & $-.153(.225)$ & $.398(.288)$ & $-.142(.221)$ \\
HCE_GDP & & $.269(.217)$ & $.386(.327)$ \\
Population & & $-.398(.284)$ & $.447(.210) *$ \\
Corruption & & $-.533(.235)$ & $-.059(.280)$ \\
Timing issue & & $12.031(.196) * * *$ & $-.451(.219) *$ \\
Constant & $.233 .023(.188) * * *$ & .146 & $12.019(.177) * * *$ \\
$\mathrm{R}^{2}$ & 92 & 92 & .356 \\
Observations & & & 92 \\
\hline
\end{tabular}

${ }^{*} p<.05 ; * * p<.01 ; * * * p<.001$

We have checked the variance inflation factor (VIF) to detect multicollinearity for each independent variable. Any individual VIF greater than ten could influence multicollinearity on the least square regression coefficient estimates. The VIF values of this study are below four, suggesting that the interpretation of the findings does not cause multicollinearity problems. The VIF values are 2.95, 2.88, 1.11, 1.41, 1.70, 2.88, $3.43,1.42,2.51$, and 1.51 for power distance, individualism, masculinity, uncertainty avoidance, long-term orientation, indulgence, healthcare expenditure out of GDP (HCE_GDP), population density, and corruption, respectively. We also calculate the incremental $\mathrm{R}$ square $(.025, .051, .029, .085, .005, .004)$ to assess the incremental validity of $\mathrm{R}$ square for all independent variables positively correlated with uncertainty avoidance, $R_{t}$ is negatively correlated with uncertainty avoidance.

Table 4 presents the results of the relationship between the confirmed COVID-19 cases and individuals' cultural dimensions across nations. The results of Column 1 show that coefficients of individualism $(\beta=0.890, p=0.000)$, masculinity $(\beta=0.444, p=0.024)$, and uncertainty avoidance $(\beta=0.451, p=0.031)$ are positive and statistically significant, suggesting that these three cultural dimensions of Hofstede affect the severity of the confirmed cases. The findings in Column 2 show that the control variables are not statistically significant, indicating that the total number of confirmed cases cannot be explained by these variables. After adding control variables (Column 3 ), the coefficients of individualism $(\beta=0.669, p=0.028)$, masculinity $(\beta=0.340$, $p=0.037)$ and uncertainty avoidance $(\beta=0.714, p=0.000)$ are positive and significantly associated with confirmed cases, which is consistent with the first hypothesis that the cultural differences are associated with more confirmed COVID-19 cases. These results support the conclusion that in countries with strong individualism, strong masculinity, and high uncertainty avoidance culture are associated with more confirmed COVID-19 cases.

Table 5 presents the results of the relationship between the COVID-19 related deaths and individuals' cultural dimensions among countries. The findings in Column 1 indicate that the coefficients of individualism $(\beta=0.954$, $p=0.000)$, masculinity $(\beta=0.587, p=0.000)$, and uncertainty avoidance $(\beta=0.704, p=0.000)$ are significantly positive, indicating these cultural dimensions impact the magnitude of overall deaths through cultural differences across the world. The findings in Column 2 show that the coefficients of corruption and timing issues are negatively significant with respect to total deaths. After incorporating the control variables in Column 3, the coefficients of individualism $(\beta=0.806, p=0.004)$, masculinity $(\beta=0.421$, $p=0.037)$, and uncertainty avoidance $(\beta=1.012, p=0.000)$ are positively and significantly associated with total deaths, which is consistent with the second hypothesis, suggesting the cultural differences influence total COVID-19 deaths. Thus, countries with strong individualism, strong masculinity, and a high uncertainty avoidance culture are associated with more COVID-19 related deaths.

Table 6 provides the results of the relationship between the growth rate of confirmed cases and Hofstede's cultural dimensions across nations. The result of Column 1 shows that the coefficients of individualism $(\beta=0.316, p=0.037)$ and uncertainty avoidance $(\beta=0.332, p=0.000)$ are positive and statistically significant, indicating that these cultural dimensions affect the severity of the growth rate of confirmed cases. After adding four control variables in Column 3 , the coefficients of individualism $(\beta=0.290, p=0.022)$ 
Table 5 Regression results of total deaths on cultural dimensions and control variables
Table 6 Regression results of the growth rate of confirmed cases on cultural dimensions and control variables

\begin{tabular}{llll}
\hline Dependent variable: & & & \\
\hline Deaths & $(1) \beta(\mathrm{SE})$ & $(2) \beta(\mathrm{SE})$ & $(3) \beta(\mathrm{SE})$ \\
\hline Power distance & $.402(.320)$ & & $.388(.324)$ \\
Individualism & $.954(.315) * * *$ & $.806(.320) * *$ \\
Masculinity & $.587(.212) * * *$ & & $.421(.199) *$ \\
Uncertainty avoidance & $.704(.225) * * *$ & & $1.012(.225) * * *$ \\
Long-term orientation & $-.146(.242)$ & & $-.344(.246)$ \\
Indulgence & $-.200(.247)$ & & $-.129(.237)$ \\
HCE_GDP & & $.487(.321)$ & $.315(.350)$ \\
Population & & $-.644(.316) *$ & $.615(.224) * *$ \\
Corruption & & $-.590(.262) *$ & $-.253(.299)$ \\
Timing issue & & $7.977(.219) * * *$ & $-.494(.234) *$ \\
Constant & $7.967(.206) * * *$ & .160 & $7.961(.189) * * *$ \\
$\mathrm{R}^{2}$ & .273 & 92 & .419 \\
Observations & 92 & 92 \\
\hline
\end{tabular}

${ }^{*} p<.05 ; * * p<.01 ; * * * p<.001$

We calculate the incremental $\mathrm{R}$ square $(.009, .057, .030, .132, .004$, and .002$)$ to assess the incremental validity of $R$ square for all independent variables

\begin{tabular}{llll}
\hline Dependent variable: & & & \\
\hline Growth Rate & $(1) \beta(\mathrm{SE})$ & $(2) \beta(\mathrm{SE})$ & $(3) \beta(\mathrm{SE})$ \\
\hline Power distance & $.143(.152)$ & & $.187(.166)$ \\
Individualism & $.316(.149) *$ & $.290(.164) *$ \\
Masculinity & $-.008(.100)$ & & $-.011(.102)$ \\
Uncertainty avoidance & $.332(.107) * * *$ & & $.370(.115) * * *$ \\
Long-term orientation & $-.155(.114)$ & & $-.179(.126)$ \\
Indulgence & $-.058(.117)$ & $.214(.149)$ & $-.094(.121)$ \\
HCE_GDP & & $.068(.113)$ & $.214(.179)$ \\
Population & & $-.099(.147)$ & $.188(.153)$ \\
Corruption & & $.212(.122) *$ & $.028(.153)$ \\
Timing issue & & $4.824(.102) * * *$ & $.227(.120) *$ \\
Constant & $4.821(.097) * * *$ & .046 & $4.819(.096) * * *$ \\
$\mathrm{R}^{2}$ & .142 & 92 & .199 \\
Observations & 92 & & 92 \\
\hline
\end{tabular}

${ }^{*} p<.05 ; * * p<.01 ; * * * p<.001$

We also calculate the incremental $\mathrm{R}$ square $(.025, .051, .029, .085, .005, .004)$ to assess the incremental validity of $\mathrm{R}$ square for all independent variables and uncertainty avoidance $(\beta=0.370, p=0.000)$ are positively and significantly associated with the growth rate of confirmed cases. Stated differently, a faster growth rate of confirmed cases is associated with nations exhibiting strong individualism and higher uncertainty avoidance. The coefficients of HCE_GDP, population density, and corruption are all negligible, indicating that these factors lack the explanatory capacity for the growth rate difference of confirmed cases across nations.
Table 7 presents the regression across-country results of the relationship between the COVID-19 $\mathrm{R}_{\mathrm{t}}$ and individuals' cultural dimensions. The results in Column 1 reveal that the coefficient of power distance $(\beta=0.058, p=0.045)$ is a key factor in the transmission of infectious diseases as seen by cultural differences around the world. After including HCE_GDP, population, corruption, and the timing issue as control variables in Column 3 , the findings specify that the coefficient of power distance $(\beta=0.062, p=0.043)$ is 
Table 7 Regression results of effective reproduction number $\left(\mathrm{R}_{\mathrm{t}}\right)$ on cultural dimensions and control variables

Dependent variable:

Effective Reproduction Number $\left(\mathrm{R}_{\mathrm{t}}\right)$

\begin{tabular}{llll}
\hline & $(1) \beta(\mathrm{SE})$ & $(2) \beta(\mathrm{SE})$ & $(3) \beta(\mathrm{SE})$ \\
\hline Power distance & $.058(.029) *$ & & $.062(.032) *$ \\
Individualism & $-.034(.028)$ & & $-.035(.032)$ \\
Masculinity & $.013(.019)$ & & $.012(.020)$ \\
Uncertainty avoid- & $-.032(.020)$ & & $-.033(.022)$ \\
$\quad$ ance & & & $-.021(.024)$ \\
Long-term orienta- & $-.020(.022)$ & & \\
$\quad$ tion & & & $-.085(.023)$ \\
Indulgence & $-.034(.022)$ & & $-.025(.035)$ \\
HCE_GDP & & $-.015(.028)$ & $-.021(.022)$ \\
Population & & $.012(.021)$ & $-.004(.030)$ \\
Corruption & & $.006(.027)$ & $-.044(.023)$ \\
Timing issue & & $-.042(.023) *$ & $.995(.189) * * *$ \\
Constant & $.994(.189) * * *$ & $.994(.019) * * *$ & $.992)$ \\
$\mathrm{R}^{2}$ & .089 & .041 & .139 \\
Observations & 92 & 92 & 92 \\
\hline
\end{tabular}

${ }^{*} p<.05 ; * * p<.01 ; * * * p<.001$

We also calculate the incremental $\mathrm{R}$ square $(.025, .051, .029, .085$, $.005, .004)$ to assess the incremental validity of $\mathrm{R}$ square for all independent variables

significantly positive, suggesting that a higher effective reproduction number $\left(\mathrm{R}_{\mathrm{t}}\right)$ is associated with nations exhibiting high power distances, which is consistent with the fourth hypothesis. The regression coefficients of all control variables are negligible, indicating that these factors lack the explanatory capacity for virus transmission.

\section{Discussion}

\section{Key Findings}

The COVID-19 pandemic has created one of the most severe public health crises in modern history. Individuals' responses to governments' control measures (e.g., lockdown, social distancing, and wearing a face mask) to contain this infectious virus vary across countries worldwide (Anderson et al., 2020), underscoring the necessity of understanding culture's impact on the outcomes of the pandemic. Therefore, we propose that culture has a novel impact on the transmission of COVID-19. We found that countries and territories with strong individualism, high uncertainty avoidance, and strong masculinity cultures were associated with the quick transmission of confirmed COVID-19 cases. Similarly, countries with strong individualism, high uncertainty avoidance, and strong masculinity cultures are associated with more COVID-19 related deaths. The results suggest that cultural differences are associated with the transmission of this infectious virus, which is consistent with the findings of cultural tightness-looseness (Gelfand et al., 2021), individualism versus tightness (Cao et al., 2020), individualism versus collectivism of COVID-19 transmission (Jiang et al., 2020), and individualistic values and infectious diseases (Morand \& Walther, 2018). Here, we show that cultural difference across different countries helps to explain COVID-19 transmission outcomes.

Some researchers have explored how culture fundamentally shapes individuals' responses to crises, such as the COVID-19 pandemic (Van Bavel et al., 2020). For example, the rapid transmission of this virus among individuals has been widely confirmed. People in individualistic countries (e.g., the UK, France, Italy, Spain, and the US) are less inclined to adopt preventive measures due to having greater freedoms, which are associated with increasing the total number of infected cases and deaths (Gelfand et al., 2021). On the other hand, countries with collectivist cultures (e.g., China, Singapore, and Vietnam) undertook control measures and thus succeeded in curbing the spread of this virus (Lu et al., 2021). Similarly, Cao et al. (2020) and Gelfand et al. (2021) claimed that collectivistic and tight cultures (e.g., China, Singapore, and South Korea) are more effective in dealing with the number of confirmed COVID-19 cases and deaths because they are more easily adopt cooperative behaviors. In addition, high uncertainty avoidance nations (e.g., France, Italy, Spain, Colombia, and Turkey) were sluggish in enforcing control measures to stop the spread of this virus. Similarly, high masculine cultures (e.g., Italy, India, Germany, and the US) that did not comply with control measures properly were associated with more confirmed cases and deaths.

Research shows that some interventions can strengthen the social norms surrounding behaviors meant to stop the transmission of the virus (e.g., social distancing, lockdown, and wearing a face mask), particularly in individualistic cultures (Gelfand et al., 2021). Certain cultural and psychological factors are associated with higher transmission of COVID-19 (Biddlestone et al., 2020). Consistent with prior research, our findings also indicate that the growth rate of confirmed cases is associated with nations exhibiting strong individualism (e.g., Belgium, Italy, and the US) and high uncertainty avoidance (e.g., Serbia, Peru, and Jordan). Therefore, in the beginning, countries with strong individualism and high uncertainty avoidance that did not properly implement the preventive measures to control the COVID-19 pandemic and where people were allowed to endure the disease, were associated with a higher growth rate of COVID cases. We further found that the infectious disease transmission measured by the effective reproduction number $\left(R_{t}\right)$ is associated with high power distance. Thus, higher $R_{t}$ is 
associated with an increase across nations with high power distances (e.g., Peru, Jordan, India, and Slovakia) that were slower to implement restrictive measures (e.g., maintaining a lockdown, social distancing, and using a face mask) or did not implement them properly at the beginning of the pandemic. However, some countries (e.g., China, South Korea, and Singapore) with a high power distance culture are successful in containing the COVID-19 pandemic due to properly following the restrictive measures (Dickens et al., 2020). Thus, the overall findings are consistent with prior research showing that cultural and psychological factors ( Biddlestone et al., 2020), social distancing (Huynh, 2020), global trends (Jones et al., 2008), and human behavior (Van Bavel et al., 2020) have significant impacts on infectious disease transmission.

\section{Implications}

The influence of culture on health is generally recognized and accepted (Napier et al., 2014). Hence, our study supports the existing literature by highlighting how cultural differences affect infectious disease transmission. When any new infectious disease is identified, we must consider the symptoms and treatments system as well as the cultural impact on the infection rate. Cross-cultural research supports the idea that different people have different perspectives on illness (e.g., supernatural, natural, and social causes) (Kahissay et al., 2017). Our study reflects cultural differences by depicting the close relationship between COVID19 and its spreading rate. Therefore, increased knowledge of individuals' cultural differences and values regarding any health crisis may lead to improved mutual understanding among countries. Our findings provide a new standpoint for preparing for later COVID-19 waves and future pandemics that can be applied to a particular cultural context to manage the pandemic and mitigate its negative economic and social effects.

Because COVID-19 is spreading globally, research on the cultural level factors that potentially influence the transmission of COVID-19 across different countries is important. The spread of this virus and its effects can not only be influenced by demographics, health care characteristics, and health status but also by cultural factors. Now new strains of the virus have emerged, such as those which started in the UK, India, and South Africa, and these can spread much faster than the original COVID-19. Some scientists also predict that other new virus strains will develop and that subsequent waves of the pandemic will last for another 4-5 years, one virus variant after another (Kissler et al., 2020). Therefore, our model can be used to predict how quickly these new viruses will spread through countries.

Chen and Biswas (2021) and Usman et al. (2021) claimed the COVID-19 pandemic differs significantly from previous pandemics in terms of its severity, cause, and scope. Faced with a crisis like COVID-19, a government must make quick and drastic decisions and sometimes take inflexible steps that recognize the need to accelerate citizens' interests. Indeed, the effectiveness of a government's crisis management depends on individuals' behavior and thus how culture affects behavior. Therefore, such effectiveness needs to be made based on the understanding of culture by the government, especially regarding how national culture influences individuals' behavior. Thus, our study can help governments in the decision-making process in any health crisis.

Our findings have suggested that countries with strong individualism were not successful in limiting the number of COVID-19 deaths and confirmed cases. Because people from loose cultures prioritize their freedom and privacy (Gelfand et al., 2011), they are less inclined to adopt different control measures properly during the pandemic. Research in psychology and behavioral economics has found that it is possible to change social norms on a broad range of behaviors (Gelfand et al., 2021). Thus, new initiatives are required to change countries' social norms in the face of COVID-19 and any future health threats.

\section{Conclusion}

Which cultural characteristics across the globe are shaping the transmission of the COVID-19? To shed light on this question, we examined the association between individuals' cultural dimensions and the transmission of COVID-19. As predicted, we found a significant cultural impact with regard to the transmission of COVID-19. Specifically, this study showed that individualism, masculinity, and uncertainty avoidance have a positive impact on the numbers of confirmed COVID-19 cases. The relationships between cultural differences and the total number of COVID-19 deaths were also positive. Our findings also indicate that the growth rate of confirmed cases is associated with the nations exhibiting strong individualism and higher uncertainty avoidance scores. Finally, we further found that infectious disease transmission measured by higher effective reproduction number $\left(\mathrm{R}_{\mathrm{t}}\right)$ is also associated with nations exhibiting a high power distance.

This current study has limitations, which need to be discussed. Our study is limited to using pandemic data from 92 countries, although the epidemic situation may vary in different territories and countries. Consequently, our study's findings may not be consistent with future data. Future research could be conducted, including all countries around the world using the most up-to-date COVID-19 data. 
Funding National Natural Science Foundation of China under (Grant \#72172132) and the Xiamen University COVID-19 Emergency Response Research Funds.

Data availability The data that support the findings of this study has been attached as supplementary material.

\section{Declarations}

Conflict of Interest The authors have no potential conflicts of interest to disclose.

Informed Consent Informed consent was not obtained because this study had not any human interaction.

\section{References}

Alfano, V., \& Ercolano, S. (2020). The Efficacy of Lockdown Against COVID-19: A Cross-Country Panel Analysis. Applied Health Economics and Health Policy, 18(4), 509-517. https://doi.org/ 10.1007/s40258-020-00596-3

Anderson, R. M., Heesterbeek, H., Klinkenberg, D., \& Hollingsworth, T. D. (2020). How will country-based mitigation measures influence the course of the COVID-19 epidemic? The Lancet, 395(10228), 931-934. https://doi.org/10.1016/S0140-6736(20) 30567-5

Bentzen, J. S. (2012). How Bad is Corruption? Cross-Country Evidence. Review of Development Economics, 16(1), 167-184. https://doi.org/10.1111/j.1467-9361.2011.00653.x

Biddlestone, M., Green, R., \& Douglas, K. M. (2020). Cultural orientation, power, belief in conspiracy theories, and intentions to reduce the spread of COVID-19. British Journal of Social Psychology, 59(3), 663-673. https://doi.org/10.1111/bjso.12397

Brockner, J. (2003). Unpacking Country Effects: On the Need To Operationalize the Psychological Determinants of Cross-National Differences. Research in Organizational Behavior, 25(3), 333-367. https://doi.org/10.1016/S0191-3085(03)25008-5

Caicedo-Ochoa, Y., Rebellón-Sánchez, D. E., Peñaloza-Rallón, M., Cortés-Motta, H. F., \& Méndez-Fandiño, Y. R. (2020). Effective Reproductive Number estimation for initial stage of COVID-19 pandemic in Latin American Countries. International Journal of Infectious Diseases, 95, 316-318. https://doi.org/10.1016/j.jid. 2020.04.069

Cao, C., Li, N., \& Liu, L. (2020). Do national cultures matter in the containment of COVID-19? International Journal of Sociology and Social Policy, 40(9/10), 939-961. https://doi.org/10.1108/ IJSSP-07-2020-0334

Chan, A. W. H., \& Yan, H. (2016). Extraversion, individualism, and M \& A activities. International Business Review, 25(1), 356-358. https://doi.org/10.1016/j.ibusrev.2015.05.011

Chen, Y., \& Biswas, M. I. (2021). Turning Crisis into Opportunities: How a Firm Can Enrich Its Business Operations Using Artificial Intelligence and Big Data during COVID-19. Sustainability, 13(22), 1-17. https://doi.org/10.3390/SU132212656

Cherneski, J. (2020). Evidence-loving rock star chief medical officers: Female leadership amidst COVID-19 in Canada. Gender, Work and Organization, 27(5), 1-14. https://doi.org/10.1111/gwao. 12494

Dickens, B. L., Koo, J. R., Lim, J. T., Park, M., Quaye, S., Sun, H., Sun, Y., Pung, R., Wilder-Smith, A., Yi, L., Chai, A., Lee, V. J., \& Cook, A. R. (2020). Modeling lockdown and exit strategies for
COVID-19 in Singapore. The Lancet Regional Health - Western Pacific, 1, 1-7. https://doi.org/10.1016/j.lanwpc.2020.10

Félix, S., de Lourdes, M., Ribeiro, I., Cunha, B., Ramalho, S., Vaz, A. R., Machado, P. P. P., \& Conceição, E. (2021). A preliminary study on the psychosocial impact of COVID-19 lockdown in post-bariatric surgery women: The importance of eating behavior, health care access, and social support. Current Psychology, 40(12), 6275-6281. https://doi.org/10.1007/S12144-021-01529-6/ TABLES/3

Fincher, C. L., Thornhill, R., Murray, D. R., \& Schaller, M. (2008). Pathogen prevalence predicts human cross-cultural variability in individualism/collectivism. Proceedings of the Royal Society $b$ : Biological Sciences, 275(1640), 1279-1285. https://doi.org/10. 1098/RSPB.2008.0094

Gelfand, M. J., Jackson, J. C., Pan, X., Nau, D., Pieper, D., Denison, E., Dagher, M., Van Lange, P. A. M., Chiu, C. Y., \& Wang, M. (2021). The relationship between cultural tightness-looseness and COVID-19 cases and deaths: A global analysis. The Lancet Planetary Health, 5(3), 135-144. https://doi.org/10.1016/S25425196(20)30301-6

Gelfand, M. J., Raver, J. L., Nishii, L., Leslie, L. M., Lun, J., Lim, B. C., Duan, L., Almaliach, A., Ang, S., Arnadottir, J., Aycan, Z., Boehnke, K., Boski, P., Cabecinhas, R., Chan, D., Chhokar, J., D’Amato, A., Ferrer, M., Fischlmayr, I. C., \& Yamaguchi, S. (2011). Differences between tight and loose cultures: A 33-nation study. Science, 332(6033), 1100-1104. https://doi.org/10.1126/ science. 1197754

Greenhalgh, T., Schmid, M. B., Czypionka, T., Bassler, D., \& Gruer, L. (2020). Face masks for the public during the covid-19 crisis. The BMJ, 369, 1-4. https://doi.org/10.1136/bmj.m1435

Greenstone, M., \& Nigam, V. (2020). Does Social Distancing Matter? The University of Chicago, Becker Friedman Institute for Economics Working Paper. doi:https://doi.org/10.2139/ssrn.3561244

Han, S., Kang, T., Salter, S., \& Yoo, Y. K. (2010). A cross-country study on the effects of national culture on earnings management. Journal of International Business Studies, 41(1), 123-141. https:// doi.org/10.1057/jibs.2008.78

Hellriegel, D., Slocum, L., \& Woodman, R. (1992). Organizational behavior (2nd ed.). West Publishing.

Henrich, J. (2015). Culture and social behavior. Current Opinion in Behavioral Sciences, 3, 84-89. https://doi.org/10.1016/j.cobeha. 2015.02.001

Heppner, P. P. (2008). Expanding the Conceptualization and Measurement of Applied Problem Solving and Coping: From Stages to Dimensions to the Almost Forgotten Cultural Context. American Psychologist, 63(8), 805-816. https://doi.org/10.1037/0003-066X. 63.8.805

Hetherington, M. J., \& Weiler, J. D. (2009). Authoritarianism and polarization in American politics. Cambridge University Press. https://doi.org/10.1111/j.1467-9221.2010.00810.x

Hofstede, G., Hofstede, G. J., \& Minkov, M. (2010). Cultures and organizations: Software of the mind. McGraw-Hill.

Hofstede, G. H. (1980). Culture's consequences: International differences in work-related values. Sage Publications.

Hsiang, S., Allen, D., Annan-Phan, S., Bell, K., Bolliger, I., Chong, T., Druckenmiller, H., Huang, L. Y., Hultgren, A., Krasovich, E., Lau, P., Lee, J., Rolf, E., Tseng, J., \& Wu, T. (2020). The effect of large-scale anti-contagion policies on the COVID-19 pandemic. Nature, 584(7820), 262-267. https://doi.org/10.1038/ s41586-020-2404-8

Hult, G. T. M., Ketchen, D. J., Griffith, D. A., Finnegan, C. A., Gonzalez-Padron, T., Harmancioglu, N., Huang, Y., Talay, M. B., \& Cavusgil, S. T. (2008). Data equivalence in cross-cultural international business research: Assessment and guidelines. Journal of International Business Studies, 39(6), 1027-1044. https://doi. org/10.1057/palgrave.jibs.8400396 
Huynh, T. L. D. (2020). Does culture matter social distancing under the COVID-19 pandemic? Safety Science, 130,. https://doi.org/10. 1016/j.ssci.2020.104872

Ibanez, A., \& Sisodia, G. S. (2020). The role of culture on 2020 SARS-CoV-2 Country deaths: A pandemic management based on cultural dimensions. GeoJournal. https://doi.org/10.1007/ s10708-020-10306-0

Jiang, S., Wei, Q., \& Zhang, L. (2020). Impacts of Cultural Difference on the Transmission of COVID-19: Individualism vs . Collectivism. Available at SSRN: https://ssrn.com/Abstract=3646229. doi:https://doi.org/10.13140/RG.2.2.34274.96966

Jones, K. E., Patel, N. G., Levy, M. A., Storeygard, A., Balk, D., Gittleman, J. L., \& Daszak, P. (2008). Global trends in emerging infectious diseases. Nature, 451(7181), 990-993. https://doi.org/ 10.1038/nature06536

Kahissay, M. H., Fenta, T. G., \& Boon, H. (2017). Beliefs and perception of ill-health causation: A socio-cultural qualitative study in rural North-Eastern Ethiopia. BMC Public Health, 17(1), 124. https://doi.org/10.1186/s12889-017-4052-y

Khataee, H., Scheuring, I., Czirok, A., \& Neufeld, Z. (2021). Effects of social distancing on the spreading of COVID-19 inferred from mobile phone data. Scientific Reports, 11, 1661. https://doi.org/ 10.1038/s41598-021-81308-2

Kim, H. S., Sherman, D. K., \& Updegraff, J. A. (2016). Fear of Ebola: The Influence of Collectivism on Xenophobic Threat Responses. Psychological Science, 27(7), 935-944. https://doi.org/10.1177/ 0956797616642596

Kissler, S. M., Tedijanto, C., Goldstein, E. M., Grad, Y. H., \& Lipsitch, M. (2020). Projecting the transmission dynamics of SARS-CoV-2 through the post-pandemic period. MedRxiv, 368, 860-868. https://doi.org/10.1101/2020.03.04.20031112

Kucharski, A. J., Klepac, P., Conlan, A. J. K., Kissler, S. M., Tang, M. L., Fry, H., Gog, J. R., Edmunds, W. J., Emery, J. C., Medley, G., Munday, J. D., Russell, T. W., Leclerc, Q. J., Diamond, C., Procter, S. R., Gimma, A., Sun, F. Y., Gibbs, H. P., Rosello, A., \& Simons, D. (2020). Effectiveness of isolation, testing, contact tracing, and physical distancing on reducing transmission of SARSCoV-2 in different settings: A mathematical modelling study. The Lancet Infectious Diseases, 20(10), 1151-1160. https://doi.org/10. 1016/S1473-3099(20)30457-6

Li, Y., Peng, J., \& Tao, Y. (2021). Relationship between social support, coping strategy against COVID - 19, and anxiety among home - quarantined Chinese university students : A path analysis modeling approach. Current Psychology. https://doi.org/10.1007/ s12144-021-02334-x

Liu, M., Thomadsen, R., \& Yao, S. (2020). Forecasting the spread of COVID-19 under different reopening strategies. Scientific Reports, 10(1), 1-8. https://doi.org/10.1038/s41598-020-77292-8

Lu, J. G., Jin, P., \& English, A. S. (2021). Collectivism Predicts Mask Usage During the COVID-19 Pandemic. PNAS, 118(23). doi:https://doi.org/10.1073/pnas.2021793118/-/DCSupplemental. Published

Lunn, P. D., Belton, C. A., Lavin, C., McGowan, F. P., Timmons, S., \& Robertson, D. A. (2020). Using Behavioral Science to help fight the Coronavirus. Journal of Behavioral Public Administration, 3(1), 1-15. https://doi.org/10.30636/jbpa.31.147

Maridal, J. H. (2013). Cultural impact on national economic growth. Journal of Socio-Economics, 47, 136-146. https://doi.org/10. 1016/j.socec.2012.08.002

Matthay, M. A., Aldrich, J. M., \& Gotts, J. E. (2020). Rational use of face masks in the COVID-19 pandemic. The Lancet, 8(May), 434-436. https://doi.org/10.1016/S2213-2600(20)30134-X
Morand, S., \& Walther, B. A. (2018). Individualistic values are related to an increase in the outbreaks of infectious diseases and zoonotic diseases. Scientific Reports, 8(1), 1-9. https://doi.org/10.1038/ s41598-018-22014-4

Napier, A. D., Ancarno, C., Butler, B., Calabrese, J., Chater, A., Chatterjee, H., Guesnet, F., Horne, R., Jacyna, S., Jadhav, S., Macdonald, A., Neuendorf, U., Parkhurst, A., Reynolds, R., Scambler, G., Shamdasani, S., Smith, S. Z., Stougaard-Nielsen, J., Thomson, L., \& Woolf, K. (2014). Culture and health. The Lancet, 384(9954), 1607-1639. https://doi.org/10.1016/S0140-6736(14)61603-2

Oran, D. P., \& Topol, E. J. (2020). Prevalence of Asymptomatic SARSCoV-2 Infection : A Narrative Review. Annals of Internal Medicine, 173(5), 362-367. https://doi.org/10.7326/M20-3012

Plümper, T., \& Neumayer, E. (2020). Lockdown policies and the dynamics of the first wave of the Sars-CoV-2 pandemic in Europe. Journal of European Public Policy. https://doi.org/10.1080/13501 763.2020 .1847170

Triandis, H. C. (2001). Individualism-collectivism and personality. Journal of Personality, 69(6), 907-924. https://doi.org/10.1111/ 1467-6494.696169

Trompenaars, F. (1994). Riding the waves of culture(1st ed.)New York: Irwin.

Tsui, A. S., Nifadkar, S., \& Ou, A. Y. (2007). Cross-national, crosscultural organizational behavior research: Advances, gaps, and recommendations. Journal of Management, 33(3), 426-478. https://doi.org/10.1177/0149206307300818

Tylor, E. B. (1871). Primitive Culture (Vol. 1). J.P. Putnam's Sons.

Usman, M., Cheng, J., Ghani, U., Gul, H., \& Shah, W. U. (2021). Social support and perceived uncertainties during COVID-19: Consequences for employees' wellbeing. Current Psychology. https:// doi.org/10.1007/s12144-021-02293-3

Van Bavel, J. J., Baicker, K., Boggio, P. S., Capraro, V., Cichocka, A., Cikara, M., Crockett, M. J., Crum, A. J., Douglas, K. M., Druckman, J. N., Drury, J., Dube, O., Ellemers, N., Finkel, E. J., Fowler, J. H., Gelfand, M., Han, S., Haslam, S. A., Jetten, J., \& Willer, R. (2020). Using social and behavioural science to support COVID19 pandemic response. Nature Human Behaviour, 4(5), 460-471. https://doi.org/10.1038/s41562-020-0884-z

Webster, G. D., Howell, J. L., Losee, J. E., Mahar, E. A., \& Wongsomboon, V. (2021). Culture, COVID-19, and collectivism: A paradox of American exceptionalism? Personality and Individual Differences, 178, 110853. https://doi.org/10.1016/j.paid.2021.110853

Willmott, R. (2000). The Place of Culture in Organization Theory: Introducing the Morphogenetic Approach. Organization, 7(1), 95-128. https://doi.org/10.1177/135050840071006

Xiao, W. S. (2021). The Role of Collectivism-Individualism in Attitudes Toward Compliance and Psychological Responses During the COVID-19 Pandemic. Frontiers in Psychology, 12, 5063. https://doi.org/10.3389/FPSYG.2021.600826/BIBTEX

Yamauchi, T., Takeuchi, S., Yamano, Y., Kuroda, Y., \& Nakadate, T. (2019). Estimation of the effective reproduction number of influenza based on weekly reports in Miyazaki Prefecture. Scientific Reports, 9(1), 1-9. https://doi.org/10.1038/s41598-019-39057-w

Yan, B., Zhang, X., Wu, L., Zhu, H., \& Chen, B. (2020). Why Do Countries Respond Differently to COVID-19? A Comparative Study of Sweden, China, France, and Japan. American Review of Public Administration, 50(6-7), 762-769. https://doi.org/10. 1177/0275074020942445

Publisher's Note Springer Nature remains neutral with regard to jurisdictional claims in published maps and institutional affiliations. 